\title{
Erratum to:
}

\section{Study of the structural, electrical and optical properties of $\mathrm{Ge}-\mathrm{Pb}-\mathrm{Te}$ nanocrystals}

Eur. Phys. J. D 70, 264 (2016), DOI: 10.1140/epjd/e2016-70307-2

Iman A. Mahdy ${ }^{1}$, Manal A. Mahdy ${ }^{2, a}$, and S. M. El Sheikh ${ }^{3}$

1 Physics department, Faculty of Science (Girls), Al-Azhar University, 11753 Nasr City, Cairo, Egypt

2 Solid State Physics Department, National Research Centre, 12622 Dokki, Giza, Egypt

3 Physics department, Faculty of Science and Engineering, American University in Cairo, 11835 New Cairo, Egypt

Received 22 December 2016

Published online 14 February 2017 - C EDP Sciences, Società Italiana di Fisica, Springer-Verlag 2017

Abstract. This erratum corrects a mistake happened in Figure 1 in the article. In the recent version Figure 1 is incorrect, we need to exchange it with the correct figure attached with this erratum.

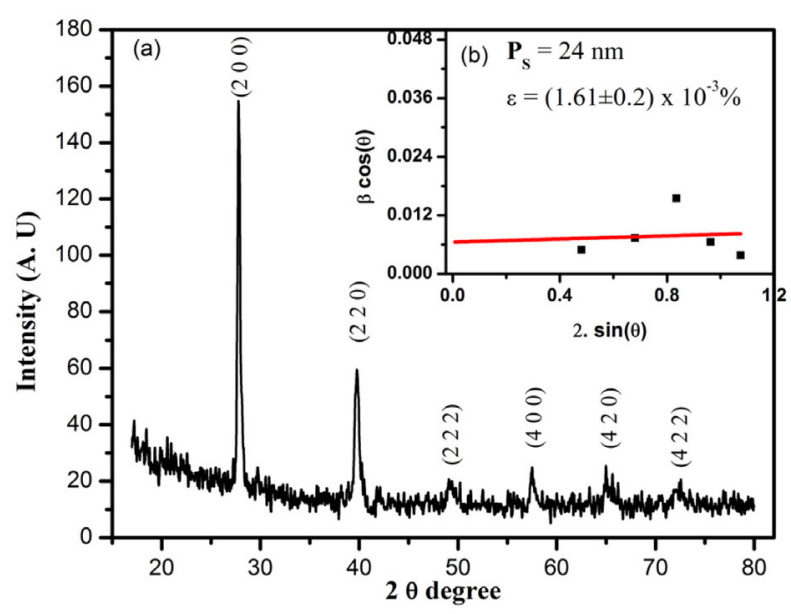

Fig. 1. 